\title{
SINGLET OXYGEN REACTIVITY IN WATER-RICH SOLVENT MIXTURES
}

\author{
Cristina Sousa \\ Departamento de Química, Universidade de Évora, Largo dos Colegiais 2, 7000 Évora, Portugal \\ Ana Maria Botelho do Rego and Teresa Sá e Melo* \\ Centro de Química-Física Molecular, Instituto Superior Técnico, Universidade Técnica de Lisboa, 1049-001 Lisboa, Portugal \\ Recebido em 18/7/07; aceito em 17/12/07; publicado na web em 31/7/08

\begin{abstract}
The 3-methylindole (3MI) oxygenation sensitized by psoralen (PSO) has been investigated in 100\%, 20\% and 5\% $\mathrm{O}_{2}$-saturated water/ dioxane $\left(\mathrm{H}_{2} \mathrm{O} / \mathrm{Dx}\right)$ mixtures. The lowering of the ${ }^{1} \mathrm{O}_{2}{ }^{*}$ chemical rate when water $\left(\mathrm{k}_{\text {chems }}{ }^{3 \mathrm{MI}}=1.4 \times 109 \mathrm{M}^{-1} \mathrm{~s}^{-1}\right)$ is replaced by deuterated water $\left(\mathrm{k}_{\mathrm{chem} \Delta}{ }^{3 \mathrm{MI}}=1.9 \times 108 \mathrm{M}^{-1} \mathrm{~s}^{-1}\right)$ suggests that hydrogen abstraction is involved in the rate determining step. A high dependence of the chemical rate constant on water concentration in $\mathrm{H}_{2} \mathrm{O} / \mathrm{Dx}$ mixtures was found showing that water molecules are absolutely essential for the success of the $3 \mathrm{MI}$ substrate oxidation by ${ }^{1} \mathrm{O}_{2}{ }^{*}$ in water-rich solvent mixtures.
\end{abstract}

Keywords: singlet oxygen; psoralen; solvent effects.

\section{INTRODUCTION}

Photosensitized reactions induced in biological substrates such as proteins or enzymes, and the characterization of the peroxide photoproducts, ${ }^{1}$ after absorption of light by drugs (antibiotics, dyes and psoralens) are important to assess drugs phototoxicity. ${ }^{2}$ To clarify the mechanism of substrate photodegradation induced by a photosensitizer like psoralen (PSO), it is important to characterize the transient species formed after PSO excitation through its photophysical parameters.

Due to the very short singlet excited state, lifetimes of psoralen (PSO, the parent compound), in water/dioxane mixtures $\leq 1 \mathrm{~ns}$, the photoinduced chemical reaction will occur from PSO triplet state. Moreover, triplet state produces singlet oxygen $\left({ }^{1} \mathrm{O}_{2}{ }^{*}\right)$ by energy transfer, which can in turn react with substrates by type II photodynamic mechanism. ${ }^{3}$

In a previous work we have determined the PSO triplet lifetimes $\left(\tau_{\mathrm{T}}\right)$ and quantum yields $\left(\Phi_{\mathrm{T}}\right)$, in water/dioxane mixtures $\left(\mathrm{H}_{2} \mathrm{O} / \mathrm{Dx}\right)$ and in a set of 16 organic solvents. ${ }^{4}$ We have reported that triplet formation quantum yield, $\Phi_{\mathrm{T}}$, of PSO is a linear function of water concentration in $\mathrm{H}_{2} \mathrm{O} / \mathrm{Dx}$ solvent mixtures, increasing from 0.033 in Dx to 0.495 in water. ${ }^{4}$ These major changes in triplet yield with media are an important factor for the efficiency of light-induced cell killing, as expected for a mechanism based on intermediate generation of singlet molecular oxygen.

On the other hand, it is well-known that the lifetimes $\left(\tau_{\Delta}\right)$ of the near-IR emission of ${ }^{1} \mathrm{O}_{2}{ }^{*}$, detected at $1270 \mathrm{~nm}$, show an enormous solvent dependence, ${ }^{5}$ varying from $\sim 3.5 \mu$ s in water to $68 \mu$ s in deuterated water. ${ }^{6}$ In addition, the ${ }^{1} \mathrm{O}_{2}{ }^{*}$ luminescence quantum yield, $\Phi_{\mathrm{P}}$ in water is very low $\left(6.5 \times 10^{-7}\right)$ whereas in deuterated water it is 19 times greater. ${ }^{7}$ One way or other, the observed ${ }^{1} \mathrm{O}_{2}{ }^{*}$ quenching by substrate whether via energy transfer, charge transfer or chemical reaction is always additive to the quenching by the solvent. Particularly, this is the case in hydroxylic solvents with abstractable hydrogen atoms. ${ }^{8}$ The bimolecular character of $\tau_{\Delta}$ quenching by the solvent, firstly reported by M. Rodgers, ${ }^{9}$ is clearly observed in $(\mathrm{H}, \mathrm{D})_{2} \mathrm{O} / \mathrm{Dx}$ solvent mixtures. ${ }^{10}$ We found (see Appendix) that those reported data in (H,D) ${ }_{2} \mathrm{O} / \mathrm{Dx}$ (10) can be fitted $\left(R^{2}=0.9976\right)$ to the Equations:

\footnotetext{
*e-mail: teresasamelo@ist.utl.pt
}

$\mathrm{k}_{\Delta}\left(\mathrm{H}_{2} \mathrm{O} / \mathrm{Dx}\right)=\mathrm{k}_{0}+\mathrm{k}_{\mathrm{Dx}}[\mathrm{Dx}]+\mathrm{k}_{\mathrm{H}_{2} \mathrm{O}}\left[\mathrm{H}_{2} \mathrm{O}\right]$

$$
\mathrm{k}_{\Delta}\left(\mathrm{D}_{2} \mathrm{O} / \mathrm{Dx}\right)=\mathrm{k}_{0}+\mathrm{k}_{\mathrm{Dx}}[\mathrm{Dx}]+\mathrm{k}_{\mathrm{D}_{2} \mathrm{O}}\left[\mathrm{D}_{2} \mathrm{O}\right]
$$

where $\mathrm{k}_{\mathrm{Dx}},=3665 \mathrm{M}^{-1} \mathrm{~s}^{-1}, \mathrm{k}_{\mathrm{H}_{2} \mathrm{O}}=3887 \mathrm{M}^{-1} \mathrm{~s}^{-1}$ and $\mathrm{k}_{\mathrm{D}_{2} \mathrm{O}}=275 \mathrm{M}^{-1} \mathrm{~s}^{-1}$ are the bimolecular rate constants, $\mathrm{k}_{0}=2.3 \times 10^{-4} \mathrm{~s}^{-1}$ is the spontaneous emission of isolated ${ }^{1} \mathrm{O}_{2}{ }^{*}$ molecules and $[\mathrm{Dx}],\left[\mathrm{H}_{2} \mathrm{O}\right]$ or $\left[\mathrm{D}_{2} \mathrm{O}\right]$ are the molar concentration of the solvents.

Thus, the direct determination of ${ }^{1} \mathrm{O}_{2}{ }^{*}$ emission quenching $\left(\mathrm{k}_{\mathrm{Q}}{ }^{\Delta}\right.$ $=\mathrm{k}_{\text {phys }}{ }^{\Delta}+\mathrm{k}_{\text {chem }}{ }^{\Delta}$ ) by substrates, in water solution (where intrinsic $\Phi_{\mathrm{P}}=$ $6.5 \times 10^{-7}$ and $1 / \tau_{\Delta}=1 / 3.5 \mu \mathrm{s}^{-1}$, as stated above), is very difficult and poorly documented in literature. For that very reason, some authors recommend to use $\mathrm{D}_{2} \mathrm{O}$ to perform studies in water ${ }^{8}$ although, as it is shown here, results cannot be extrapolated to $\mathrm{H}_{2} \mathrm{O}$ case.

For the above reasons, the overall ${ }^{1} \mathrm{O}_{2}{ }^{*}$ quenching by biological targets reported in literature are always determined in solvents for which ${ }^{1} \mathrm{O}_{2}{ }^{*}$ intrinsic lifetime (and emission intensity) are high enough to be accurately measured. For instance, in deuterated water $\tau_{\Delta}$ $=68 \mu \mathrm{s}$, in Dx $\tau_{\Delta}=27 \mu \mathrm{s}$, in MeCN $\tau_{\Delta}=58 \mu \mathrm{s}$, in EtOH $\tau_{\Delta}=13 \mu \mathrm{s}$, and in a mixture of both, $1: 1 \mathrm{v} / \mathrm{v} \mathrm{D}_{2} \mathrm{O} / \mathrm{EtOH}, \tau_{\Delta}=21 \mu \mathrm{s} .{ }^{5,11}$ In those solvents, the ${ }^{1} \mathrm{O}_{2}{ }^{*}$ overall quenching with a good oxidable substrate such as 3-methylindole (3MI) has been reported with rate constants, $\mathrm{k}_{\mathrm{Q}}{ }^{\Delta}$, of $1.6 \times 10^{8} \mathrm{M}^{-1} \mathrm{~s}^{-1}$ in $1: 1 \mathrm{v} / \mathrm{v} \mathrm{D}_{2} \mathrm{O} / \mathrm{EtOH}^{11}, 3.2 \times 10^{8} \mathrm{M}^{-1} \mathrm{~s}^{-1}$ in $\mathrm{D}_{2} \mathrm{O}^{13}, 6.8 \times 10^{7} \mathrm{M}^{-1} \mathrm{~s}^{-1}$ in $\mathrm{MeCN}^{12}$ and $5.6 \times 10^{7} \mathrm{M}^{-1} \mathrm{~s}^{-1}$ in Dx. ${ }^{12}$ The chemical part, $\mathrm{k}_{\text {chem }{ }^{3 \mathrm{MI}}}$, of the ${ }^{1} \mathrm{O}_{2}{ }^{*}$ quenching by $3 \mathrm{MI}$ has values of $1.20 \times 10^{8} \mathrm{M}^{-1} \mathrm{~s}^{-1}$ in $1: 1 \mathrm{v} / \mathrm{v} \mathrm{D}_{2} \mathrm{O} / \mathrm{EtOH},{ }^{11} 1.34 \times 10^{8} \mathrm{M}^{-1} \mathrm{~s}^{-1}$ in $\mathrm{D}_{2} \mathrm{O},{ }^{12}$ $2.3 \times 10^{6} \mathrm{M}^{-1} \mathrm{~s}^{-1}$ in $\mathrm{MeCN},{ }^{11,13}$ and $\leq 1.0 \times 10^{6} \mathrm{M}^{-1} \mathrm{~s}^{-1}$ in Dx. (this work). It can be observed that $\mathrm{k}_{\text {chem } \Delta}{ }^{3 \mathrm{MI}} / \mathrm{k}_{\text {phys } \Delta}{ }^{3 \mathrm{MI}}$ ratio increases with increasing hydroxylic character of the solvent and its number of abstractable $\mathrm{H}$ atoms.

As described above, the overall ${ }^{1} \mathrm{O}_{2}{ }^{*}$ quenching by substrate $\left(\mathrm{k}_{\mathrm{Q} \Delta}{ }^{3 M I}\right.$ $=\mathrm{k}_{\text {phys } \Delta}{ }^{3 \mathrm{MI}}+\mathrm{k}_{\text {chem } \Delta}{ }^{3 \mathrm{MI}}$ ) is very difficult to be determined in water solution. On the other hand, the chemical part of this rate $\left(\mathrm{k}_{\text {chem } \Delta}{ }^{3 \mathrm{MI}}\right)$ can only be measured by steady state irradiation experiments, regardless the solvent used. These values are very time-consuming and some authors claimed they are difficult to obtain. ${ }^{14}$ Unfortunately, the most recent reviews on the subject are only concerned with the physical part of the ${ }^{1} \mathrm{O}_{2}{ }^{*}$ deactivation processes. ${ }^{7}$

Due to the lack of experimental data, the role of water molecules on the ${ }^{1} \mathrm{O}_{2}{ }^{*}$ chemical reaction with substrates is not clear. Because of 
the low activation energy for singlet oxidation reactions processes $(0.5-8 \mathrm{kcal})$, there is no temperature effect on the rate of such photoreaction. ${ }^{15}$ It is claimed that solvents play no role in the chemical reaction with substrates and it will only affect the lifetime of singlet oxygen by the solvent polarity/polarizability effects. ${ }^{16}$ Moreover, these studies have additional difficulties to obtain simultaneously $\mathrm{k}_{\text {chem } \Delta}{ }^{3 \mathrm{MI}}$ and $\mathrm{k}_{\mathrm{Q} \Delta}{ }^{3 \mathrm{MI}}$ values in nonpolar and highly polar solvents, due to the insolubility of the most common biological substrates in water. Nevertheless, a contrasting result has been reported for naphthalenic substrates with a 142 times increase on $\mathrm{k}_{\text {chem } \Delta}{ }_{3 \mathrm{MI}}$ (45 times increases on $\mathrm{k}_{\mathrm{Q} \Delta}{ }^{3 \mathrm{MI}}$ ) when going from methanol to water solutions, without any reasonable quantitative explanation. ${ }^{16}$ The crucial role of water to the [4+2] cycloaddition between ${ }^{1} \mathrm{O}_{2}{ }^{*}$ and electron-rich para-alkyl phenols was also recently reported. ${ }^{17}$

Some analyses were performed in linear multi-parameter fits using solvatochromic properties providing some physical insight for the charge transfer induced ${ }^{1} \mathrm{O}_{2}{ }^{*}$ quenching, ${ }^{16,17}$ but the physical meaning of such enhancement, particularly the role of water in the chemical reactivity remains unclear.

Steady state irradiation procedure using variable concentrations of water in solvent mixtures is the only way to evidence the role of the $\mathrm{H}$ atoms in the ${ }^{1} \mathrm{O}_{2}{ }_{2}$ chemical quenching mechanism in aqueous solution.

The kinetics and quantum yields of PSO triplet state, as a function of water concentration in $\mathrm{H}_{2} \mathrm{O} / \mathrm{Dx}$, were taken from our previous work. ${ }^{4}$ Since the intrinsic $\tau_{\Delta}$ lifetimes have already been reported for the same $(\mathrm{H}, \mathrm{D})_{2} \mathrm{O} / \mathrm{Dx}$ solvent mixtures,${ }^{10}$ it would be possible to test PSO ability to induce substrate oxidation by singlet oxygen $\left({ }^{1} \mathrm{O}_{2}^{*}\right)$, as a function of water concentration.

We have chosen an easily oxidizable substrate such as 3-methylindole (3MI) instead of 3-alanilindole (tryptophan, Trp) to perform a steady state irradiation of PSO. In fact, the alanine substitution increases the aqueous and non-aqueous solubility of this derivative relatively to Trp. In addition, the solvent dependent emission of the indole ring is easily detected. Moreover, methyl substitution at 3 position of the indole ring was shown to highly increase its photoreactivity. ${ }^{11,14}$

Making use of psoralen as photosensitizer, we have accomplished a kinetic study on the decrease of $3 \mathrm{MI}$ substrate concentration as a function of PSO irradiation time, by changing: the water concentration in $(\mathrm{H}, \mathrm{D})_{2} \mathrm{O} / \mathrm{Dx}$ solvent mixtures and thus the PSO triplet formation quantum yields; the molecular oxygen concentration, using 5, 20 and $100 \% \mathrm{O}_{2}$-saturated solutions; the substrate (3MI) and the photosensitizer (PSO) ground state concentrations; the singlet oxygen lifetime, using dioxane solvent mixtures with water or deuterated water.

From the resulting data we extracted information about both type I and type II kinetic mechanisms, involving (3PSO* +3MI) and (3MI $\left.+{ }^{1} \mathrm{O}_{2}{ }^{*}\right)$ direct pathways, respectively.

In this work we show that $3 \mathrm{MI}$ photodegradation induced by psoralen is highly dependent on the concentration of water molecules in the aqueous solvent mixtures.

\section{EXPERIMENTAL}

Psoralen and 3-methylindole were reagents commercially available from Sigma. Deuterium oxide was purchased from Aldrich. The solvents 1,4-dioxane (spectroscopic grade) and absolute ethanol (HPLC grade) were provided by Merck. The solvent, dioxane (and 3MI compound), came from freshly open bottles or kept frozen during storage to avoid oxidation and peroxide formation.

Pure water was obtained from deionised tap water that was first distilled and then evaporated in a quartz still. Binary solvent mixtures were prepared with water (or with sodium (di) hydrogenophosphate buffer) making the mixture volumetrically complete with dioxane. The solvents dioxane and water are miscible in all proportions. Moreover, the sensitizer PSO $(10 \mu \mathrm{M})$ and the substrate $3 \mathrm{MI}(200$ to $480 \mu \mathrm{M})$ are completely soluble in the solvent mixtures used.

Steady state irradiations were performed in a home-made setup using a high-pressure $200 \mathrm{~W}$ mercury arc lamp. The $365 \mathrm{~nm} \mathrm{Hg}$ line was isolated with optical and chemical filters. Sample was bubbled with the appropriate gas $\left(\mathrm{O}_{2}, \mathrm{~N}_{2}\right.$ or a mixture of 5 or $20 \% \mathrm{O}_{2}$ in $\left.\mathrm{N}_{2}\right)$ and submitted to magnetic stirring to avoid photoproducts damage during irradiation. Temperature was kept constant by the use of a cell-holder thermostat. The decrease in $3 \mathrm{MI}$ substrate concentration with irradiation time was monitored by fluorescence measurements in a SPEX Fluorolog 2. The maximum fluorescence intensity of indole derivative was monitored at $368 \mathrm{~nm}$ for an excitation wavelength at $310 \mathrm{~nm}$. The fluorescence excitation was chosen at $310 \mathrm{~nm}$ because, at this wavelength, the $3 \mathrm{MI}$ absorption extinction coefficient is low and thus, we can make solutions with high substrate concentrations without inner filter effects $\left(\varepsilon_{\mathrm{G}}=233 \mathrm{M}^{-1} \mathrm{~s}^{-1}\right)$.

The UVA irradiation at $365 \mathrm{~nm}$, with a fluence rate of $11.7 \mathrm{~mJ} \mathrm{~s}^{-1}$ determined by ferrioxalate actinometry, ${ }^{18}$ is only absorbed by PSO photosensitizer. The psoralen concentration is kept constant $(10 \mu \mathrm{M})$, in the irradiated volume $(5 \mathrm{~mL})$. The PSO absorption extinction coefficient at $365 \mathrm{~nm}$ vary from 1100 to $1450 \mathrm{M}^{-1} \mathrm{~cm}^{-1}$ in dioxane to water solutions, respectively.

The substrate photodegradation was monitored by the decrease in the $3 \mathrm{MI}$ fluorescence intensity at the maximum of its emission band, where PSO emission is absent (see Figure 1). No changes on 3MI emission band shape were observed in samples with irradiation time. In this study no attempts were made to analyze the photoproducts.

The infrared emission of ${ }^{1} \mathrm{O}_{2}{ }^{*}$ was measured with a liquid nitrogen-cooled germanium photodiode detector (403HS, Edinburgh Instruments). A $355 \mathrm{~nm}$ Nd-YAG laser, $7 \mathrm{~mJ}$ intensity and $7 \mathrm{~ns}$ pulse width was used to excite the sensitizer (Minilite II, Continuum). The $1270 \mathrm{~nm}$ signal was recorded in a 12 bit transient recorder (TR1202, FastComTec) and transferred to a PC. Both IR interference filter at $1270 \mathrm{~nm}$ (1270BP50) and a $1000 \mathrm{~nm}$ cut-off filter (LL-1000-F) were used. The Ge-detector with a preamplifier, (surface area of $0.25 \mathrm{~cm}^{2}$ in a sapphire window) operates at a bias of $-300 \mathrm{~V}$, supplied by a HV power supply (PS3, Edinburgh Instruments). Aqueous ludox scatter solutions were used to monitoring the fast decay signal due to the apparatus function. Both unwanted signals, i.e, the fundamental at $1064 \mathrm{~nm}$ from the laser excitation and the fluorescence from NIR filters, were eliminated by putting a filter $(\% \mathrm{~T}=0.08$ at $1064 \mathrm{~nm})$, on the laser excitation beam. However this operation decreases by $28 \%$ the $355 \mathrm{~nm}$ laser excitation energy. For this reason we used ZnTPP instead of PSO because a factor of 4 was found on relative $\Phi_{\Delta}$ values obtained from optically matched solutions. The quenching of ${ }^{1} \mathrm{O}_{2}$. decay by increased $3 \mathrm{MI}$ concentrations were determined in air-saturated toluene solutions, using the synthetic 5,10,15,20 tetraphenyl-21H,23H-porphin, zinc (ZnTPP). The ${ }^{1} \mathrm{O}_{2}$ * quenching rate by $3 \mathrm{MI}$ in $\mathrm{D}_{2} \mathrm{O}$ solutions was already reported in literature, where TPP or methylene blue were employed as sensitizers. ${ }^{12}$

The time profiles of the PSO triplet-triplet absorption were determined by the third harmonic excitation light $(355 \mathrm{~nm})$ of a Nd:YAG laser from a Spectra Physics time-resolved flash photolysis equipment. Solutions were prepared by bubbling $\mathrm{N}_{2}$ followed by vacuum degassing. Samples were monitored at the maximum of T-T absorbance at $450 \mathrm{~nm}$. The overall rate constants, $\mathrm{k}_{\mathrm{Q}}{ }^{3 \mathrm{MI}}=\mathrm{k}_{\mathrm{phys}}{ }^{3 \mathrm{MI}}+$ $\mathrm{k}_{\mathrm{chem}}{ }^{3 \mathrm{MI}}$, (see Scheme 1) of PSO triplet state quenching by 3 MI substrate molecules in degassed solutions, were used in aerobic conditions for the kinetic analysis.

The 3MI photodegradation rates $(-d[3 \mathrm{MI}] / d \mathrm{t})$ were measured by fluorescence as a function of UVA irradiation time, in different oxygen saturated $(\mathrm{H}, \mathrm{D})_{2} \mathrm{O} / \mathrm{Dx}$ mixtures. 
The chemical rate constants of PSO triplet reaction with 3MI $\left(\mathrm{k}_{\mathrm{chem}}{ }^{3 \mathrm{MI}}\right)$ were measured by steady-state irradiation procedure, in the absence of molecular oxygen.

Singlet oxygen lifetime values $\left(\tau_{\Delta}\right)$ in water (and deuterated water) $(\mathrm{H}, \mathrm{D})_{2} \mathrm{O} / \mathrm{Dx}$ mixtures were taken from the literature. ${ }^{10}$ The overall quenching rate constants of ${ }^{1} \mathrm{O}_{2}{ }^{*}$ by $3 \mathrm{MI}$ in $\mathrm{D}_{2} \mathrm{O}\left(3.210^{8} \mathrm{M}^{-1}\right.$ $\left.\mathrm{s}^{-1}\right)$ and in Dx $\left(5.610^{7} \mathrm{M}^{-1} \mathrm{~s}^{-1}\right)$ were taken from literature ${ }^{12}$ and used for kinetic calculations. The molecular oxygen concentration in the different solvent mixtures was determined assuming a linear additivity of the molecular oxygen solubilities, in dioxane $(7.55 \mathrm{mM})$ and in water $(1.325 \mathrm{mM})$, for oxygen saturated solutions. ${ }^{18,19}$ Water molar concentration ranged from $28 \mathrm{M}(50 \% \mathrm{v} / \mathrm{v})$ to $50 \mathrm{M}(90 \% \mathrm{v} / \mathrm{v})$ in the solvent mixtures were used in this work.

\section{RESULTS}

Figures 1 and 2 show ground state absorption and fluorescence spectra of 3MI substrate and $\mathrm{PSO}$ photosensitizer, in $\mathrm{H}_{2} \mathrm{O} / \mathrm{Dx}$ mixture (with $90 \% \mathrm{v} / \mathrm{v}$ water). It can be observed that the $365 \mathrm{~nm}$ UVA irradiation light can only be absorbed by the photosensitizer, PSO.

Since the half width of the fluorescence band of the indole derivative is unchanged with irradiation time, we assumed that photoproducts were not fluorescent at the monitored 3MI emission wavelength. Moreover, the fluorescence intensity monitored at 368 $\mathrm{nm}$ belongs only to $3 \mathrm{MI}$ emission since at this wavelength the PSO fluorescence signal is negligible, being $10^{3}$ lower than that of the indole derivative (Figure 1).

Triplet quenching of PSO molecules by 3MI substrate was studied by flash photolysis in degassed solutions. It was verified that

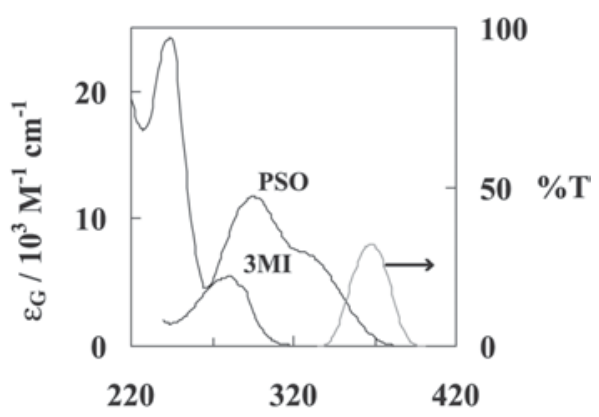

Wavelength / nm

Figure 1. Absorption spectra of sensitizer PSO and substrate 3MI in 90\% $v / v \mathrm{H}_{2} \mathrm{O} / \mathrm{Dx}$. The grey line shows the filter transmittance spectrum used for irradiations at $365 \mathrm{~nm}$

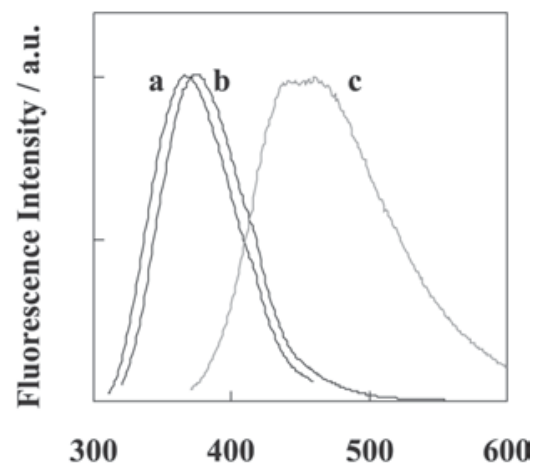

Wavelength / nm

Figure 2. 3MI fluorescence spectra before irradiation in (a) 1:1 $D_{2}$ Olethanol and (b) $\mathrm{H}_{2} \mathrm{O} / \mathrm{Dx}$ with $90 \%(\mathrm{v} / \mathrm{v})$ water. (c) PSO fluorescence spectra in the mixture $\mathrm{H}_{2} \mathrm{O} / \mathrm{D} x$ with $90 \%(\mathrm{v} / \mathrm{v})$ water the PSO triplet formation quantum yield, $\Phi_{\mathrm{T}}$, was unchanged by the isotopic substitution when water is replaced by deuterated water, in the solvent mixtures.

The lifetime of PSO triplet excited state is concentration dependent. Its triplet decay rate constant decreases linearly with increasing ground state concentration, denoting a rapid self-quenching reaction $\left(\mathrm{k}_{\mathrm{sq}}{ }^{\mathrm{T}}=1.5 \times 10^{9} \mathrm{M}^{-1} \mathrm{~s}^{-1}\right)$, in $\mathrm{H}_{2} \mathrm{O} /$ Dx mixtures. ${ }^{4}$ For all psoralen derivatives, the observed triplet self-quenching rates have nearly diffusion limited values, but the exact nature of this excited-state association is unknown.

The reciprocal of the observed PSO triplet lifetime plotted as a function of the 3MI substrate concentrations were determined by laser flash photolysis. The observed rate constant is given by Equation 3:

$\mathrm{k}_{\mathrm{Q}}{ }^{\mathrm{T}}=\mathrm{k}_{0}{ }^{\mathrm{T}}+\mathrm{k}_{\mathrm{sq}}{ }^{\mathrm{T}}[\mathrm{PSO}]+\mathrm{k}_{\mathrm{Q}}{ }^{3 \mathrm{MI}}[3 \mathrm{MI}]$

where $\left(\mathrm{k}_{0}{ }^{\mathrm{T}}+\mathrm{k}_{\mathrm{sq}}{ }^{\mathrm{T}}[\mathrm{PSO}]\right)$ and $\mathrm{k}_{\mathrm{Q}}{ }^{\mathrm{T}}$ are the reciprocal of the observed PSO triplet lifetimes in the absence and in the presence of $3 \mathrm{MI}$ substrate, respectively.

The values for the sum $\left(\mathrm{k}_{0}{ }^{\mathrm{T}}+\mathrm{k}_{\mathrm{sq}}{ }^{\mathrm{T}}\right.$ [PSO] $)$ of $(3.6 \pm 0.6) \times 10^{5} \mathrm{~s}^{-1}$ and $(3.1 \pm 0.1) \times 10^{5} \mathrm{~s}^{-1}$ were obtained in $90 \% \mathrm{v} / \mathrm{v}_{2} \mathrm{O}$ and $\mathrm{D}_{2} \mathrm{O}$ in dioxane, respectively. These results compare with those obtained for PSO triplet self quenching in water ${ }^{20}$ and in ethano. ${ }^{12}$

The overall triplet quenching by $3 \mathrm{MI}$, is the sum of both physical and chemical pathways $\left(\mathrm{k}_{\mathrm{Q}}{ }^{3 \mathrm{MI}}=\mathrm{k}_{\mathrm{phys}}{ }^{3 \mathrm{MI}}+\mathrm{k}_{\mathrm{chem}}{ }^{3 \mathrm{MI}}\right)$, as shown in Scheme 1 (c $+\mathrm{d}$ processes). The flash photolysis determination of PSO triplet quenching, $\mathrm{k}_{\mathrm{Q}}{ }^{3 \mathrm{MI}}=(3.60 \pm 0.4) \times 10^{9} \mathrm{M}^{-1} \mathrm{~s}^{-1}$ and $(3.37 \pm 0.08) \times 10^{9} \mathrm{M}^{-1}$ $\mathrm{s}^{-1}$, were obtained in $90 \% \mathrm{v} / \mathrm{v}_{2} \mathrm{O}$ and $\mathrm{D}_{2} \mathrm{O}$ in dioxane, respectively. These values are of the same order of magnitude of those already reported in water, for PSO triplet quenching by tryptophan. ${ }^{20}$

The kinetics of $3 \mathrm{MI}$ photoreaction was studied by steady state irradiation procedure.

The transient species formed after PSO excitation and the deactivation pathways are shown in the Scheme 1.

After the absorption of a photon by ground state PSO, the obtained singlet excited state ( ${ }^{1} \mathrm{PSO} *$ ) readily decays to ground state or to triplet state $\left({ }^{3} \mathrm{PSO} *\right)$. The differential equation that describes the $3 \mathrm{MI}$ concentration decrease with irradiation time, assuming that the concentration of products is equal to the concentration of $3 \mathrm{MI}$ disappearing, is given by:

$-\mathrm{d}[3 \mathrm{MI}] / \mathrm{dt}=\mathrm{d}[$ Products $] / \mathrm{dt}=\mathrm{k}_{\text {chem }}{ }^{3 \mathrm{MI}}[3 \mathrm{MI}]\left[{ }^{3} \mathrm{PSO}^{*}\right]$

And

$\mathrm{d}\left[{ }^{3} \mathrm{PSO}^{*}\right] / \mathrm{dt}=\left(\mathrm{I}_{\mathrm{abs}} / \mathrm{V}\right) \Phi_{\mathrm{T}}-\left[{ }^{3} \mathrm{PSO} *\right]\left(\mathrm{k}_{0}+\mathrm{k}_{\mathrm{sq}}[\mathrm{PSO}]+\mathrm{k}_{\mathrm{Q}}{ }^{3 \mathrm{MI}}[3 \mathrm{MI}]+\right.$ $\mathrm{k}_{\mathrm{Q}}$ prod. $\left.\left([3 \mathrm{MI}]_{0}-[3 \mathrm{MI}]\right)\right)$

where $\mathrm{d}[3 \mathrm{MI}] / \mathrm{dt}$ is the experimental rate of $3 \mathrm{MI}$ degradation and rate constants are defined in Scheme I.

The solution of Equations 4 and 5 together does not yield an analytical function of [3MI] vs time. The classical approach to overcome this problem is to assume steady state conditions for the transient species, i.e., $\mathrm{d}\left[{ }^{3} \mathrm{PSO} *\right] / \mathrm{dt}=0$. Doing so, the reaction rate, $\mathrm{v}_{\mathrm{N}_{2}}$ is given by the differential Equation 6, where $\mathrm{N}_{2}$ stands for nitrogensaturated solution.

$$
\begin{gathered}
v^{N_{2}}=-\frac{d}{d t}[3 \mathrm{MI}]=\frac{k_{\text {chem }}^{3 \mathrm{MI}}[3 \mathrm{MI}]\left(I_{\text {abs }} / V\right) \Phi_{\mathrm{T}}}{k_{0}+k_{\mathrm{sq}}[\mathrm{PSO}]+k_{\mathrm{Q}}^{3 \mathrm{MI}}[3 \mathrm{MI}]+k_{\mathrm{Q}}^{\text {prod }}\left([3 \mathrm{MI}]_{0}-[3 \mathrm{MI}]\right)} \\
=\frac{k_{\mathrm{chem}}^{3 \mathrm{MI}}[3 \mathrm{MI}]\left(I_{\mathrm{abs}} / V\right) \Phi_{\mathrm{T}}}{k_{0}+k_{\mathrm{sq}}[\mathrm{PSO}]+\left(k_{\mathrm{Q}}^{3 \mathrm{MI}}-k_{\mathrm{Q}}^{\text {prod }}\right)[3 \mathrm{MI}]+k_{\mathrm{Q}}^{\text {prod }}[3 \mathrm{MI}]_{0}}
\end{gathered}
$$




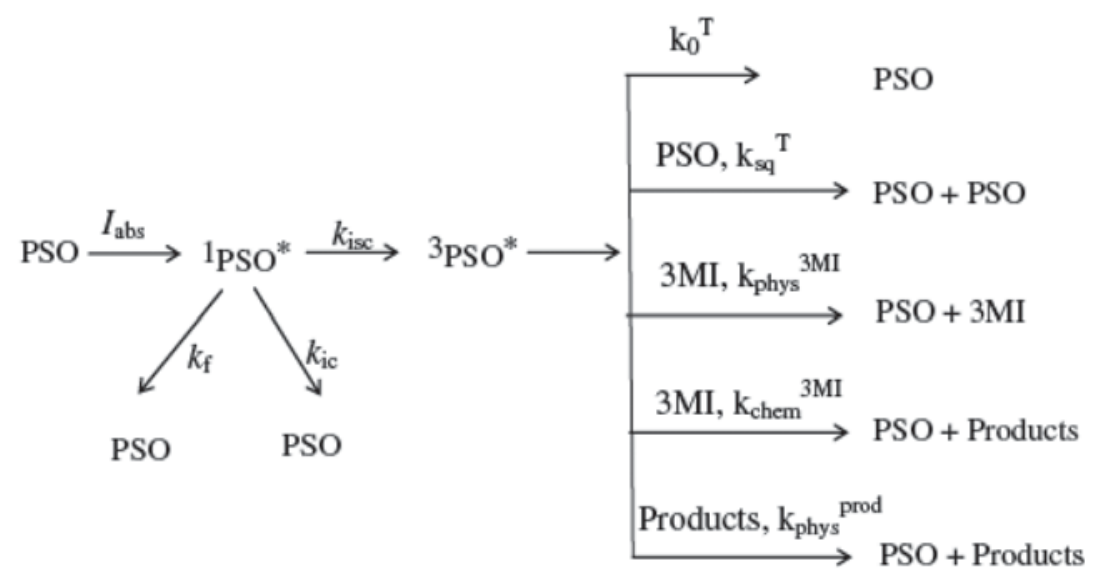

(a)

Scheme 1

where $I_{\text {abs }}$ is the PSO absorption intensity, $V$ is the volume of irradiated solution, $\Phi_{\mathrm{T}}$ is the triplet formation quantum yield and $t$ the irradiation time. Since the observed decrease of $3 \mathrm{MI}$ concentration with the irradiation time is always exponential, it means that [3MI] should appear just in the numerator of Eq. 6. This is only true if $k_{Q}^{3 \mathrm{MI}}$ $\approx k_{Q}^{\text {prod }}$, Equation 6 becoming:

$v^{N_{2}}=-\frac{d}{d t}[3 \mathrm{MI}]=\frac{k_{\text {chem }}^{3 \mathrm{MI}}[3 \mathrm{MI}]\left(I_{\text {abs }} / V\right) \Phi_{\mathrm{T}}}{k_{0}+k_{\mathrm{sq}}[\mathrm{PSO}]+k_{\mathrm{Q}}^{\text {prod }}[3 \mathrm{MI}]_{0}} \approx \frac{k_{\text {chem }}^{3 \mathrm{MI}}[3 \mathrm{MI}]\left(I_{\text {abs }} / V\right) \Phi_{\mathrm{T}}}{k_{0}+k_{\mathrm{sq}}[\mathrm{PSO}]+k_{\mathrm{Q}}^{3 \mathrm{QII}}[3 \mathrm{MI}]_{0}}(7)$

Since the $\mathrm{k}_{0}{ }^{\mathrm{T}},+\mathrm{k}_{\mathrm{sq}}{ }^{\mathrm{T}}$ and $\mathrm{k}_{\mathrm{Q}}{ }^{3 \mathrm{MI}}$ were previously determined in $90 \% \mathrm{v} / \mathrm{v}_{2} \mathrm{O}$ and $\mathrm{D}_{2} \mathrm{O}$ in dioxane (see above), the only parameter needed to fit Equation 7 to experimental data is $\mathrm{k}_{\text {chem }}{ }^{3 \mathrm{MI}}$. From the fitting, values of $(2.39 \pm 0.2) \times 10^{8} \mathrm{M}^{-1} \mathrm{~s}^{-1}$ and $(9.07 \pm 0.5) \times 10^{8} \mathrm{M}^{-1}$ $\mathrm{s}^{-1}$ were determined for the chemical rate constant $\mathrm{k}_{\mathrm{chem}}{ }^{3 \mathrm{MI}}$, in normal and deuterated water $(90 \% \mathrm{v} / \mathrm{v})$, respectively, in nitrogen-saturated solutions. Moreover, in deuterated water, the use of different PSO concentrations leads to the same $\mathrm{k}_{\mathrm{chem}}{ }^{3 \mathrm{MI}}$ values. Therefore, in $\mathrm{D}_{2} \mathrm{O}$, an invariant value for the chemical rate constant, $\mathrm{k}_{\text {chem }}{ }^{3 \mathrm{MI}}$ was assumed.

In the absence of molecular oxygen the indole derivative, 3MI, can easily react by electron transfer to triplet PSO to yield ion radicals (Type I pathway). The formation of neutral tryptophan $\operatorname{TrpH}$ and PSO-- anion have already been described. ${ }^{21}$ In deuterated water, the hydrated electrons, $\mathrm{e}_{\mathrm{aq}}^{-}$which react rapidly with PSO $\left(\mathrm{k} \sim 10^{10} \mathrm{M}^{-1}\right.$ $\left.\mathrm{s}^{-1}\right)$, is expected to be more stabilized than in normal water. ${ }^{22}$ This may be the reason for having $\mathrm{k}_{\mathrm{O}}{ }^{3 \mathrm{MI}}\left(\mathrm{D}_{2} \mathrm{O}\right)>\mathrm{k}_{\mathrm{Q}}{ }^{3 \mathrm{MI}}\left(\mathrm{H}_{2} \mathrm{O}\right)$.

As described above, the values of the overall triplet quenching rate constants $\mathrm{k}_{\mathrm{Q}}^{3 \mathrm{MI}}\left(=\mathrm{k}_{\mathrm{phys}}{ }^{3 \mathrm{MI}}+\mathrm{k}_{\mathrm{chem}}{ }^{3 \mathrm{MI}}\right)$, were determined by laser flash photolysis. Thus, the difference $\mathrm{k}_{\mathrm{phys}}{ }^{3 \mathrm{MI}}=\mathrm{k}_{\mathrm{Q}}{ }^{3 \mathrm{MI}}-\mathrm{k}_{\text {chem }}{ }^{3 \mathrm{MI}}$ can be obtained as shown in Table 1.

Table 1. Bimolecular rate constants for PSO triplet quenching $\left(\mathrm{k}_{\mathrm{O}}{ }^{3 \mathrm{MI}}\right)$ and for PSO photoreaction $\left(\mathrm{k}_{\mathrm{chem}}{ }^{3 \mathrm{MI}}\right)$ with $3 \mathrm{MI}$, in deaerated solutions

\begin{tabular}{llll}
\hline & $\mathrm{k}_{\text {chem }}{ }^{3 \mathrm{MI}}\left(\mathrm{M}^{-1} \mathrm{~s}^{-1}\right)$ & $\mathrm{k}_{\text {phys }}{ }^{3 \mathrm{MI}}\left(\mathrm{M}^{-1} \mathrm{~s}^{-1}\right)$ & $\mathrm{k}_{\mathrm{Q}}{ }^{3 \mathrm{MI}}\left(\mathrm{M}^{-1} \mathrm{~s}^{-1}\right)$ \\
\hline $90 \% \mathrm{H}_{2} \mathrm{O} / \mathrm{Dx}$ & $(0.24 \pm 0.02) 10^{9}$ & $(3.36 \pm 0.4) \times 10^{9}$ & $(3.60 \pm 0.40) \times 10^{9}$ \\
$90 \% \mathrm{D}_{2} \mathrm{O} / \mathrm{Dx}$ & $(0.91 \pm 0.05) 10^{9}$ & $(2.46 \pm 0.1) \times 10^{9}$ & $(3.37 \pm 0.08) \times 10^{9}$ \\
\hline
\end{tabular}

It can be observed that, in the absence of molecular oxygen, the triplet quenching by $3 \mathrm{MI}$ is mainly due to a physical process rather than to a chemical one. The major physical deactivation is a diffusion controlled process with values of the same order of magnitude of those reported for PSO triplet quenching by indole derivatives. ${ }^{20}$

The kinetics of $3 \mathrm{MI}$ photooxygenation was studied by steady state irradiation in the presence of three concentrations of oxygen (5, $20,100 \%$ ) for each solution. The pathway (Type II), concerning the energy transfer from PSO triplet state to ${ }^{3} \mathrm{O}_{2}$ ground state, is operative in the presence of oxygen yielding singlet oxygen ${ }^{1} \mathrm{O}_{2}{ }^{*}$. The classical kinetic mechanism ${ }^{3}$ is shown below, in Scheme 2.
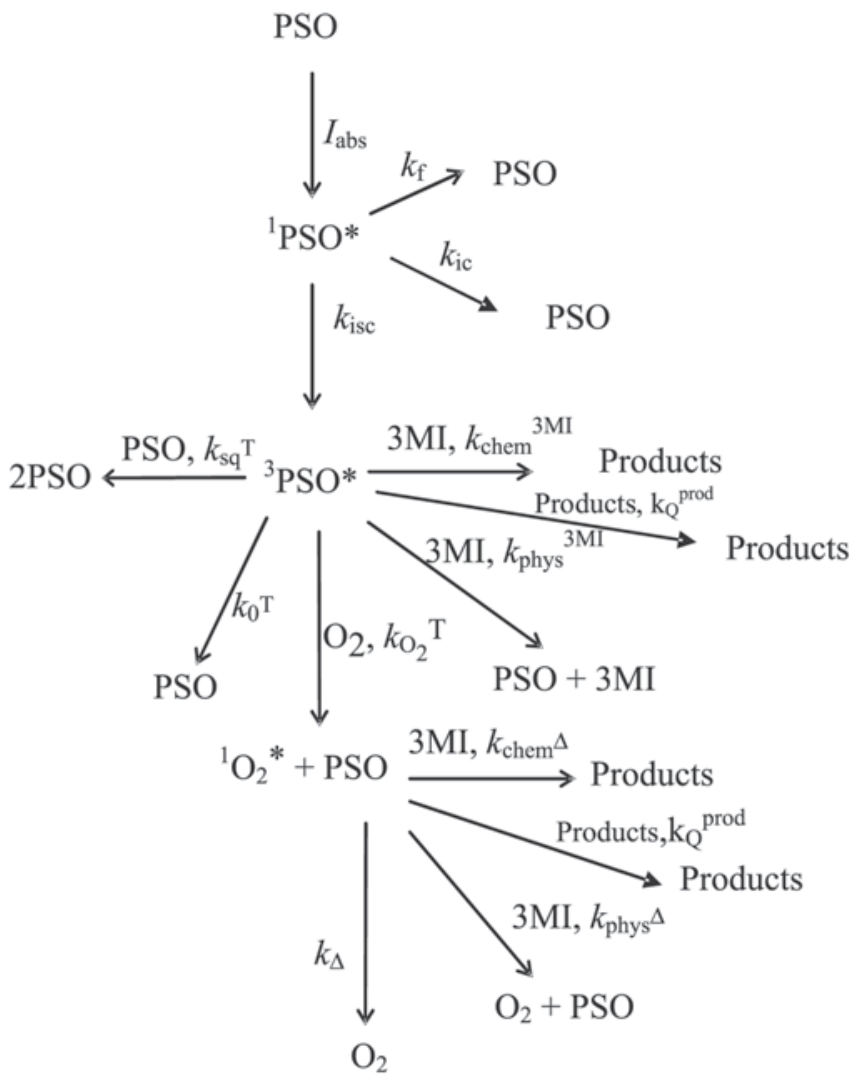

Scheme 2

Summing all the pathways, the $3 \mathrm{MI}$ photodegradation rate is given by:

$-\mathrm{d} / \mathrm{dt}[3 \mathrm{MI}]=\mathrm{K}_{\mathrm{chem}}{ }^{3 \mathrm{MI}}[3 \mathrm{MI}]\left[{ }^{3} \mathrm{PSO}^{*}\right]+\mathrm{k}_{\mathrm{chem} \Delta}{ }^{3 \mathrm{MI}}[3 \mathrm{MI}]\left[{ }^{1} \mathrm{O}_{2}{ }^{*}\right]$

Once again, since the experimental data, $\mathrm{I}_{\mathrm{f}}(\mathrm{t}) \propto[3 \mathrm{MI}](\mathrm{t})$, is a monoexponential function, the steady-state assumption for transient species can be used and Equation 9 is obtained: 


$$
\begin{aligned}
& -\frac{d[3 \mathrm{MI}]}{d t}=\frac{\left(I_{\text {abs }} / V\right) \Phi_{\mathrm{T}}[3 \mathrm{MI}]}{k_{0}^{T}+k_{s q}^{T}[\mathrm{PSO}]+k_{\mathrm{O}_{2}}^{T}\left[\mathrm{O}_{2}\right]+k_{\mathrm{Q}}^{3 \mathrm{MI}}[3 \mathrm{MI}]+k_{\mathrm{Q}}^{\text {prod }}\left([3 \mathrm{MI}]_{0}-[3 \mathrm{MI}]\right)} \times \\
& \times\left(k_{\text {chem }}^{3 \mathrm{MI}}+\frac{k_{\text {che }}^{3 \mathrm{MI}} k_{\mathrm{O}_{2}}^{T}\left[\mathrm{O}_{2}\right]}{k_{\Delta}+k_{\mathrm{Q}_{\Delta}}^{3 \mathrm{MI}}[3 \mathrm{MI}]+k_{\mathrm{Q}_{\Delta}}^{\text {prod }}\left([3 \mathrm{MI}]_{0}-[3 \mathrm{MI}]\right)}\right)
\end{aligned}
$$

where $k_{\mathrm{O}_{2}}{ }^{\mathrm{T}}$ is the bimolecular energy transfer rate constant from PSO triplet to ground state ${ }^{3} \mathrm{O}_{2}$ oxygen and $k_{\Delta}$ is the reciprocal of singlet oxygen lifetime. Constants are defined in Scheme 2. Also, since the decay is monoexponential, it means that $k_{Q}{ }^{3 \mathrm{MI}} \approx k_{Q}^{\text {prod }}$ and $k_{Q_{\Delta}}{ }^{3 \mathrm{MI}} \approx$ $k_{Q_{\Delta}}{ }^{\text {prod }} \mathrm{k}_{\mathrm{Q}}$ being the sum of the physical and chemical rate constants. Equation 9 can, therefore, be rewritten as:

$-\frac{d[3 \mathrm{MI}]}{d t}=\frac{\left(I_{\text {abs }} / V\right) \Phi_{\mathrm{T}}[3 \mathrm{MI}]}{k_{0}^{T}+k_{s q}^{T}[\mathrm{PSO}]+k_{\mathrm{O}_{2}}^{T}\left[\mathrm{O}_{2}\right]+k_{\mathrm{Q}}^{\text {rrod }}[3 \mathrm{MI}]_{0}} \times\left(k_{\mathrm{chem}}^{3 \mathrm{MI}}+\frac{k_{\mathrm{chem}}^{3 \mathrm{MI}} k_{\mathrm{O}_{2}}^{T}\left[\mathrm{O}_{2}\right]}{k_{\Delta}+k_{\mathrm{Q}_{\Delta}}^{\text {prod }}[3 \mathrm{MI}]_{0}}\right)=A[3 \mathrm{MI}]$

and, thence, $[3 \mathrm{MI}]=[3 \mathrm{MI}]_{0} \exp (-\mathrm{At})$

There are now just three parameters needed to fit Equation 10 to data: $\mathrm{k}_{\mathrm{O}_{2}}{ }^{\mathrm{T}}, \mathrm{k}_{\text {chem }}{ }_{3} \mathrm{MI}$ and, $\mathrm{k}_{\mathrm{Q}}$ prod since all the other ones were already known from experiments in the absence of oxygen and the singlet oxygen intrinsic lifetimes in (H,D) ${ }_{2} \mathrm{O} / \mathrm{Dx}$ mixtures were taken from literature. ${ }^{6}$ Data treatment has shown that the goodness of the fitting is not very sensitive to the value of $\mathrm{k}_{\mathrm{O}}{ }^{\mathrm{T}}$ and we assumed a value of $3 \times 10^{9} \mathrm{M}^{-1} \mathrm{~s}^{-1}$, the same order of magnitude as the rate of energy transfer of derivatives (8-methoxypsoralen, 3-carbethoxypsoralen, etc) triplet state to molecular oxygen, in water solutions.

In order to increase the ratio between the number of experimental points and the number of fitted parameters, values for each solvent composition (and different oxygen concentrations) were fitted together. Correlation coefficients obtained range from 0.9 to 0.999 . The experimental data and the fitted curves are shown in Figures 3 and 4, for three different $\mathrm{O}_{2}$ concentrations in solvent mixtures with different water (or deuterated water) contents.

The assumed rate constant value $\left(k_{\mathrm{O}_{2}}{ }^{\mathrm{T}}=3 \times 10^{9} \mathrm{M}^{-1} \mathrm{~s}^{-1}\right)$ is the value needed in order to obtain $\mathrm{k}_{\mathrm{O}}{ }^{3 \mathrm{MI}}$ of the order of magnitude of the reported one in $\mathrm{D}_{2} \mathrm{O}\left(\mathrm{k}_{\mathrm{Q}_{A}}{ }^{3 \mathrm{MI}}=3.2 \times 10^{8} \mathrm{M}^{-1} \mathrm{~s}^{-1}\right) .{ }^{9}$ Moreover, the fitted $k_{\mathrm{O}_{2}}{ }^{\mathrm{T}}$ value is independent of the solvent polarity, as expected for triplet energy transfer processes from carbonyl molecules to triplet molecular oxygen..$^{10,13}$

In this way, the unknown rate constants $\left(\mathrm{k}_{\mathrm{O}}{ }^{3 \mathrm{MI}}\right.$ and $\left.\mathrm{k}_{\text {chem }}{ }^{3 \mathrm{MI}}\right)$ were obtained by fitting as shown in Figures 3 and 4 . No fitting was possible using fixed values of $k_{\text {chem }}{ }^{\Delta}$. A large variation of both $k_{\mathrm{Q}}{ }^{\Delta}$ and $k_{\text {chem }}{ }^{\Delta}$ with water content was obtained. All the rate constants present in the kinetic Scheme 2 are listed in Table 2.

The overall quenching (physical + chemical) of the ${ }^{1} \mathrm{O}_{2}{ }^{*}$ by $3 \mathrm{MI}$ molecules was monitored by direct ${ }^{1} \mathrm{O}_{2}{ }^{*}$ luminescence decay at 1270 $\mathrm{nm}$. Figure 5 shows the time-resolved luminescence decays from optically matched ZnTPP and PSO in air-saturated toluene solutions. The laser beam was filtered to avoid the fundamental of the Nd-YAG at $1064 \mathrm{~nm}$ and the fluorescence of NIR filters which results in lowering $\sim 28 \%$ of the $355 \mathrm{~nm}$ laser excitation. With the temporal resolution of our equipment it was impossible to observe the ${ }^{1} \mathrm{O}_{2}{ }^{*}$ quenching by $3 \mathrm{MI}$ in water solution since $\tau_{\Delta}<<3.5 \mu \mathrm{s}$ when $3 \mathrm{MI}$ is added. The ${ }^{1} \mathrm{O}_{2}{ }^{*}$ quenching by $3 \mathrm{MI}$ was determined in air-saturated toluene $\left(\left[\mathrm{O}_{2}\right]\right.$ $=1.74 \mathrm{mM}$ ), using ZnTPP as sensitizer. As shown in Figure 5 insert, a quenching rate constant with a value of $\mathrm{k}_{\Delta}^{\text {total }}=1 \times 10^{7} \mathrm{M}^{-1} \mathrm{~s}^{-1}$ was obtained in agreement with literature value. ${ }^{13}$

\section{DISCUSSION}

The changing of rate constants with solvent properties (polarizability/polarity, acidity and basicity index and Hildebrand cavity
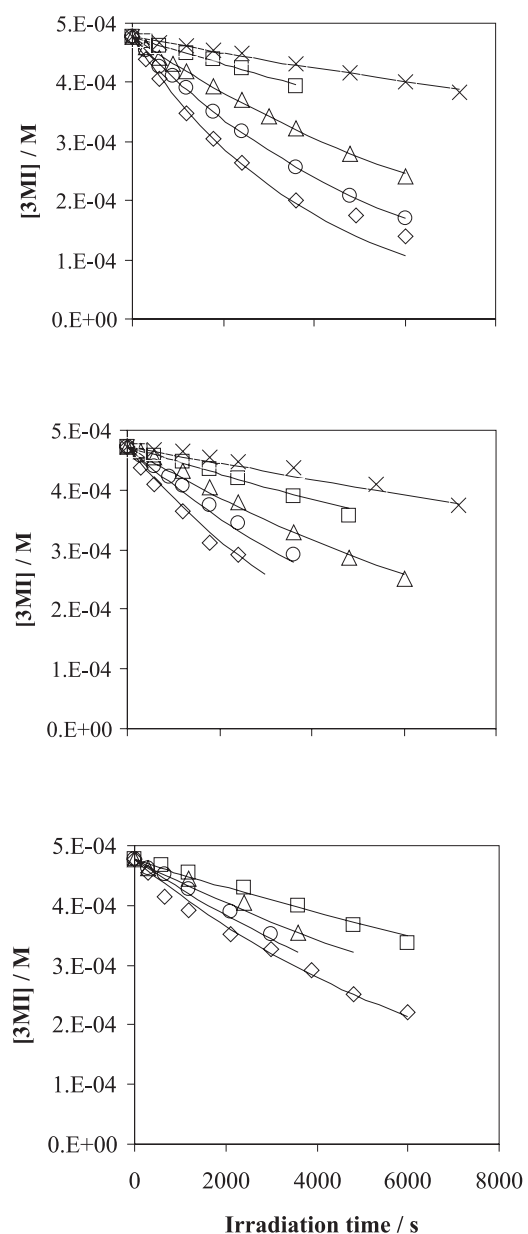

Figure 3. 3MI fluorescence intensity (excitation at $310 \mathrm{~nm}$ and fluorescence emission at $368 \mathrm{~nm}$ ) as a function of the irradiation time. Solvent mixtures were: $(\times)$ 50, ( ) 60, ( $\Delta$ ) 70, (O) 80 and $(\diamond) 90 \% \mathrm{v} / \mathrm{v}$ of deuterated water in dioxane. PSO and $3 M I$ initial concentrations were $10 \mu M$ and $477 \mu \mathrm{M}$, respectively. Solutions were kept under solvent saturated gas flow containing 100, 20 and 5\% molecular oxygen, from top to bottom

of solvents) are usually analysed through the well-known Kamlet/ Taft's and Hildebrandt solvatochromic parameters. The correlation obtained between the logarithm of a given rate constant with those solvent empirical parameters is indicative of the mechanism nature of the process characterized by that constant rate. Since in a water/ dioxane mixture, several parameters change, one way of trying to rationalize the experimental $\mathrm{k}_{\mathrm{Q}^{3}}{ }^{3 \mathrm{MI}}$ and $\mathrm{k}_{\text {chem }_{\Delta}}{ }^{3 \mathrm{MI}}$ values is to fit them to the empirical $\pi^{*}, \alpha, \beta$ and $\delta \hat{H}$ parameters of the solvent mixture. The following Equation 11 was used for that:

$\ln \mathrm{k}=\ln \mathrm{k}_{0}+\mathrm{s} \pi^{*}+\mathrm{a} \alpha+\mathrm{b} \beta+\mathrm{h} \delta \mathrm{H}^{2}$

$\pi^{*}, \alpha, \beta$ and $\delta \mathrm{H}$ being the solvent polarizability/polarity, the acidity and basicity index and the Hildebrand cavity, respectively and s, a, $\mathrm{b}$ and $\mathrm{h}$ its relative weight.

The $\pi^{*}, \alpha, \beta$ parameters of water/dioxane mixtures used in the fitting were computed from an empirical polarity scale derived from the triplet quantum yields $\left(\Phi_{\mathrm{T}}\right)$ of psoralen (PSO $)^{4}$ and derivatives, 8 -methoxypsoralen (8MOP) and 5-methoxypsoralen (5MOP) ${ }^{23}$ in a wide range of 16 pure organic solvents and a set of aqueous solvent mixtures. By taking the indicator dye 7-amino, 4-methylcoumarin (coumarin 120), whose molecular structure is closer to our furocoumarins than the commonly used $\mathrm{E}_{\mathrm{T}}(30)$ of betaine dye, an empirical scale for psoralen $\mathrm{E}_{\mathrm{T}}(\mathrm{PSO})$ was derived in order to get the correlations 

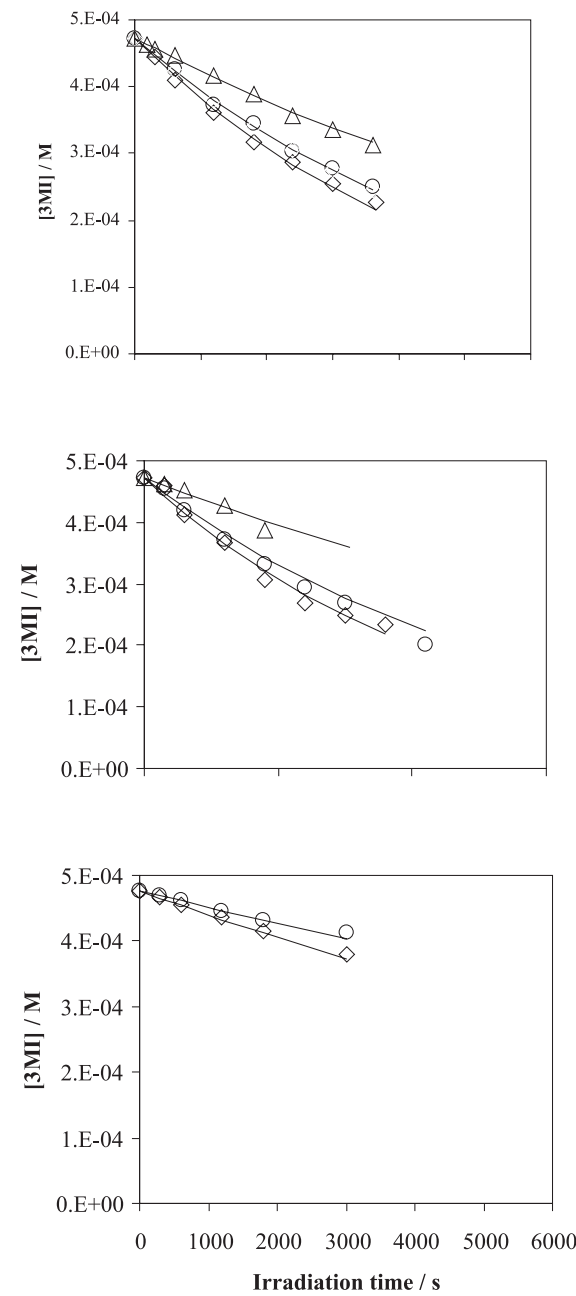

Figure 4. 3MI fluorescence intensity in function of the irradiation time. Solvent mixtures were $(\Delta) 70,(O) 80$ and $(\diamond) 90 \% \mathrm{v} / \mathrm{v}$ of water in dioxane. Experimental conditions as in Figure 3

between the reported scale $\mathrm{E}_{\mathrm{T}}(120)=26.71-2.02 \pi^{*}-1.58 \alpha-1.32$ $\beta\left(10^{3} \mathrm{~cm}^{-1}\right)^{24}$ and the $\Phi_{\mathrm{T}}$ of PSO and derivatives 8MOP and 5MOP in water/dioxane mixtures. The $\pi^{*}, \alpha$ and $\beta$ parameters, shown in Table 3 , were computed in this work for the entire range (0 to 100\%) of $\mathrm{H}_{2} \mathrm{O}$ :Dx solvent mixtures through the following relationships:

$$
\begin{array}{ll}
-\ln \Phi_{\mathrm{T}}(\mathrm{PSO})=1.83-0.57 \pi^{*}-0.78 \alpha-0.11 \beta & \mathrm{R}^{2}=0.999 \\
-\ln \Phi_{\mathrm{T}}(5 \mathrm{MOP})=2.74-2.13 \pi^{*}-0.15 \alpha-1.45 \beta & \mathrm{R}^{2}=0.992 \\
-\ln \Phi_{\mathrm{T}}(8 \mathrm{MOP})=2.23-0.65 \pi^{*}-2.19 \alpha-0.84 \beta & \mathrm{R}^{2}=0.993
\end{array}
$$

The $\pi^{*}$ parameters of the mixtures are in agreement with the

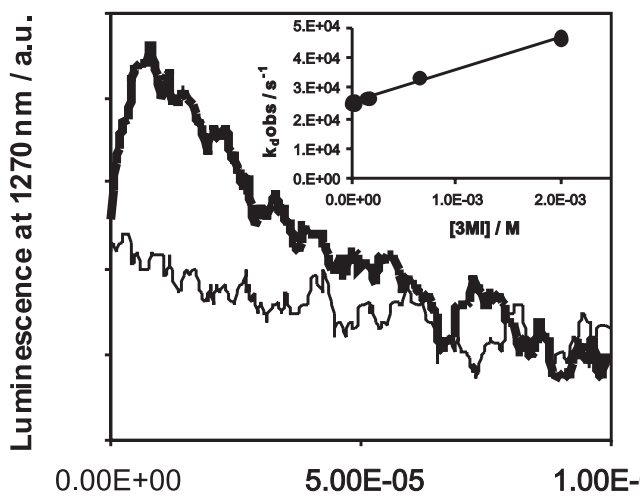

Figure 5. Time-resolved NIR luminescence traces from singlet oxygen at 1270 nm sensitized by ZnTPP (top) and sensitized by PSO (bottom) yielding a 4 times lower $\Phi_{\Delta}$ than ZnTPP, in air-saturated toluene. Luminescence traces were averaged over 200 laser pulses. Insert: $k_{d}\left(s^{-1}\right)$ rate of observed singlet oxygen decay plotted as a function of the 3 MI concentration, in air-saturated toluene solutions of ZnTPP. The overall quenching rate (physical + chemical) value is $1 \times 10^{7} \mathrm{M}^{-1} \mathrm{~s}^{-1}$

literature values. ${ }^{25}$ The same empirical parameters were assumed for $\mathrm{D}_{2} \mathrm{O}: \mathrm{Dx}$ mixtures. The fitting of the total and the chemical rates to the solvent parameters of Table 3 yield $\mathrm{h}$ and $\mathrm{b}$ virtually zero:

$\ln \mathrm{k}_{\mathrm{Q}_{\Delta}}{ }^{3 \mathrm{MI}}=5.55 \pi^{*}+11.44 \alpha$ and $\ln \mathrm{k}_{\mathrm{chem}_{\Delta}}{ }^{3 \mathrm{MI}}=5.04 \pi^{*}+11.72 \alpha$ for $\mathrm{D}_{2} \mathrm{O}$ :Dx mixtures

$\ln \mathrm{k}_{\mathrm{Q}_{\Delta}}{ }^{3 \mathrm{MI}}=5.84 \pi^{*}+12.80 \alpha$ and $\ln \mathrm{k}_{\mathrm{chem}_{\Delta}}{ }^{3 \mathrm{MI}}=5.63 \pi^{*}+12.96 \alpha$ for $\mathrm{H}_{2} \mathrm{O}$ :Dx mixtures

These results may be interpreted as a mechanism for the chemical reaction involving a hydrogen ion abstraction from water since the relative weight of parameter $\alpha$ is larger in $\mathrm{H}_{2} \mathrm{O}$ than in $\mathrm{D}_{2} \mathrm{O}$. But this conclusion could be reached even without this parametric fitting since the experimental results show that $\mathrm{k}_{\text {chem }_{\Delta}}{ }^{3 \mathrm{MI}}\left(\mathrm{D}_{2} \mathrm{O}\right)<<\mathrm{k}_{\mathrm{chem}_{\Delta}}{ }^{3 \mathrm{MI}}$ $\left(\mathrm{H}_{2} \mathrm{O}\right)$.

Another approach to rationalize the results comes from the fact that in both mixtures of $\mathrm{Dx}: \mathrm{H}_{2} \mathrm{O}$ and $\mathrm{Dx}: \mathrm{D}_{2} \mathrm{O}$, we can write $\mathrm{k}_{\text {chem }_{\Delta}}{ }^{3 \mathrm{MI}}$ $\propto\left[(\mathrm{D}, \mathrm{H})_{2} \mathrm{O}\right]^{\mathrm{n}}$ where $\mathrm{n}>>1$ for both $\mathrm{Dx}: \mathrm{H}_{2} \mathrm{O}$ and $\mathrm{Dx}: \mathrm{D}_{2} \mathrm{O}$.

This approach is supported by Equations 1 and 2 where variations of $\mathrm{k}_{\Delta \Delta}$ with the composition in $\mathrm{Dx}:(\mathrm{D}, \mathrm{H})_{2} \mathrm{O}$ was completely explainable by a collisional mechanism. Here, the larger variation with water concentration, expressed by $n=5.2$ for $\mathrm{D}_{2} \mathrm{O}$ mixtures and $\mathrm{n}=6.1$ for $\mathrm{H}_{2} \mathrm{O}$ mixtures, suggests that the reaction between $3 \mathrm{MI}$ and ${ }^{1} \mathrm{O}_{2}{ }^{*}$ should need a cage of a few water molecules, $n$ being its average number.

It was already reported in the literature the role of such comple-

\begin{tabular}{|c|c|c|c|c|c|c|c|c|}
\hline & $90 \% \mathrm{D}_{2} \mathrm{O}$ & $80 \% \mathrm{D}_{2} \mathrm{O}$ & $70 \% \mathrm{D}_{2} \mathrm{O}$ & $60 \% \mathrm{D}_{2} \mathrm{O}$ & $50 \% \mathrm{D}_{2} \mathrm{O}$ & $90 \% \mathrm{H}_{2} \mathrm{O}$ & $80 \% \mathrm{H}_{2} \mathrm{O}$ & $70 \% \mathrm{H}_{2} \mathrm{O}$ \\
\hline $\mathrm{k}_{/ \Delta} \mathrm{s}^{-1(10)}$ & $1.7 \times 10^{4}$ & $1.9 \times 10^{4}$ & $2.2 \times 10^{4}$ & $2.4 \times 10^{4}$ & $2.6 \times 10^{4}$ & $2.0 \times 10^{5}$ & $1.8 \times 10^{5}$ & $1.7 \times 10^{5}$ \\
\hline $\mathrm{k}_{0}^{\Delta \mathrm{T}} \mathrm{s}^{-1}$ & & & $2.0 \times 10^{5}$ & & & & $2.0^{\prime} 10^{5}$ & \\
\hline $\mathrm{k}_{\mathrm{sq}}{ }^{\mathrm{T}} \mathrm{M}^{-1} \mathrm{~s}^{-1}$ & & & $1.5 \times 10^{9}$ & & & & $1.5 \times 10^{9}$ & \\
\hline $\mathrm{k}_{\mathrm{O}}^{\mathrm{sq}} \mathrm{M}^{-1} \mathrm{~s}^{-1}$ & & & $3.0 \times 10^{9}$ & & & & $3.0 \times 10^{9}$ & \\
\hline $\mathrm{k}_{\text {chem }}{ }^{3}{ }^{3 \mathrm{MI}} \mathrm{M}^{-1} \mathrm{~s}^{-1}$ & & & $9.1 \times 10^{8}$ & & & & $2.4 \times 10^{8}$ & \\
\hline $\mathrm{k}_{\mathrm{Q}}^{3 \mathrm{MI}} \mathrm{M}^{-1} \mathrm{~s}^{-1}$ & & & $3.4 \times 10^{9}$ & & & & $3.6 \times 10^{9}$ & \\
\hline $\mathrm{k}_{\text {chem }}{ }^{\Delta} \mathbf{M}^{-1} \mathrm{~s}^{-1}$ & $1.8 \times 10^{8}$ & $0.9 \times 10^{8}$ & $0.4 \times 10^{8}$ & $0.2 \times 10^{8}$ & $0.1 \times 10^{8}$ & $1.2 \times 10^{9}$ & $0.8 \times 10^{9}$ & $0.3 \times 10^{9}$ \\
\hline $\mathrm{k}_{\mathrm{Q}}^{\Delta} \mathrm{M}^{-1} \mathrm{~s}^{-1}$ & $1.9 \times 10^{8}$ & $1.1 \times 10^{8}$ & $0.5 \times 10^{8}$ & $0.2 \times 10^{8}$ & $0.1 \times 10^{8}$ & $1.4 \times 10^{9}$ & $0.8 \times 10^{9}$ & $0.3 \times 10^{9}$ \\
\hline
\end{tabular}
xes in the substrate oxidation by singlet oxygen. Formation of such

Table 2. Total (physical and chemical) rate constants for the system PSO $+3 \mathrm{MI}$ in water/dioxane (or deuterated water) solvent mixtures. The values were fitted to the experiments on 100,20 and 5\% oxygen saturated solutions 
Table 3. Solvatochromic parameters $\alpha, \beta$ and $\pi^{*}$ in water/dioxane solvent mixtures

\begin{tabular}{lccc}
\hline v/v \%water & $\pi^{*}$ & $\alpha$ & $\beta$ \\
\hline 100 & 1.09 & 1.17 & 0.18 \\
90 & 1.03 & 1.17 & 0.25 \\
80 & 0.93 & 1.17 & 0.33 \\
70 & 0.80 & 1.16 & 0.43 \\
60 & 0.69 & 1.15 & 0.57 \\
50 & 0.59 & 1.10 & 0.72 \\
40 & 0.52 & 1.03 & 0.88 \\
30 & 0.50 & 0.90 & 0.96 \\
25 & 0.54 & 0.79 & 0.92 \\
20 & 0.59 & 0.66 & 0.85 \\
15 & 0.66 & 0.51 & 0.74 \\
10 & 0.70 & 0.37 & 0.65 \\
5 & 0.67 & 0.16 & 0.50 \\
0 & 0.55 & 0.00 & 0.37 \\
\hline
\end{tabular}

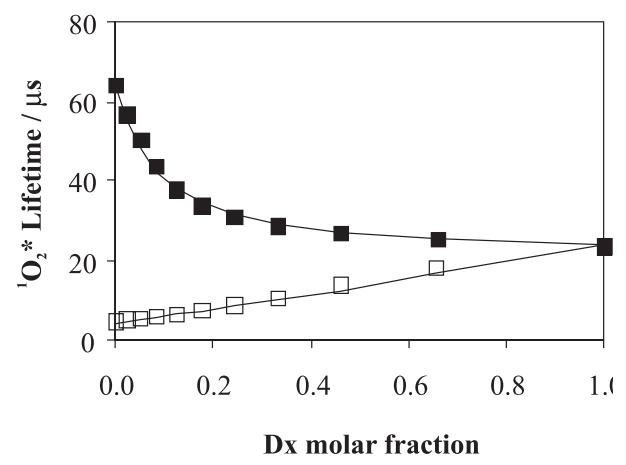

Figure 6. Singlet oxygen lifetimes in $\mathrm{D}_{2} \mathrm{O}: \mathrm{Dx}$ (full symbols) and $\mathrm{H}_{2} \mathrm{O}: \mathrm{Dx}$ (open symbols) solvent mixtures, digitalized from Ref. 10 and fitted by equation A.I with $n=m=1$ (lines)

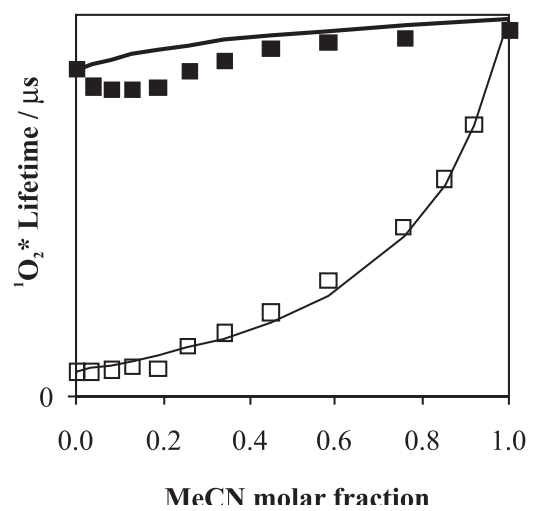

Figure 7. Singlet oxygen lifetimes in $\mathrm{D}_{2} \mathrm{O}$ :Acetonitrile (full symbols) and $\mathrm{H}_{2} \mathrm{O}$ :Acetonitrile (open symbols) solvent mixtures, digitalized from ref. 10 and fitted by Equation A.1 with $n=m=1$ (lines)

a complex is entropically unfavoured. However, a photoreaction involving 3 water molecules has been suggested to occur in cells in the presence of ${ }^{1} \mathrm{O}_{2}{ }^{* 26}$ and later confirmed by other authors. ${ }^{27}$ Another reaction involving 4 water molecules in photoinduced deprotonation of 7-hydroxyquinoline in acidic media has been reported in literature. ${ }^{28}$ The reaction of water molecules with ${ }^{1} \mathrm{O}_{2}{ }^{*}$ was first described in antibody-mediated reactions in cells ${ }^{26}$ and later confirmed by other authors. ${ }^{29,30}$

To render evident the importance of the water molecules on the ${ }^{1} \mathrm{O}_{2}{ }^{*}$ chemical reaction pathway, it was necessary the convergence of two factors which are present in the solvent mixtures used: singlet oxygen is highly electrophilic and thus the $3 \mathrm{MI}$ substrate being a good electron donor will greatly increase the substrate oxygenation, ${ }^{15}$ the optimal $\mathrm{pH}$ for ${ }^{1} \mathrm{O}_{2}{ }^{*}$ production is approximately 9.2, which is the alkaline environment of the $\mathrm{H}_{2} \mathrm{O}$ :Dx solvent mixtures. ${ }^{15,31}$

\section{CONCLUSIONS}

3-Methylindole photodegradation induced by psoralen in the presence of oxygen is highly dependent on the concentration of water molecules in the aqueous solvent mixtures with dioxane.

The kinetic scheme proposed assumes that photoproducts have a quenching effect, both on ${ }^{3} \mathrm{PSO}^{*}$ and on ${ }^{1} \mathrm{O}_{2}{ }^{*}$, identical to the quenching effect of $3 \mathrm{MI}$. This assumption is required to explain the pseudo-first order experimentally verified. Indeed, the $3 \mathrm{MI}$ concentration decrease, as a function of irradiation time, always follows an exponential law, i.e., a pseudo-first order kinetics.

The physical deactivation of singlet oxygen by $3 \mathrm{MI}$ is negligible when compared to the reactive one. Hydrogen abstraction is involved in the rate determining step since the reaction constant $\mathrm{k}_{\text {chem }}{ }_{3}{ }^{3 \mathrm{I}}$ is one order of magnitude larger in $\mathrm{H}_{2} \mathrm{O} / \mathrm{Dx}$ than in $\mathrm{D}_{2} \mathrm{O} / \mathrm{Dx}$ mixtures.

Due to the magnitude of $\tau_{\Delta}$ in water $(3.5 \mu \mathrm{s})$ and to its lowering due to the high chemical quenching rate $\left(\mathrm{k}_{\text {chem }}{ }_{3 \mathrm{MI}}>1.4 \times 10^{9} \mathrm{M}^{-1} \mathrm{~s}^{-1}\right)$, it was experimentally impossible to get directly the quenching rate of ${ }^{1} \mathrm{O}_{2}{ }^{*}$ luminescence at $1270 \mathrm{~nm}$ in the presence of $3 \mathrm{MI}$ in water, or in water-rich solutions of the solvent mixtures.

The solvatochromic parameters analysis shows that the weight of parameter a is larger than the weight of parameter $\pi^{*}$, the former being larger in $\mathrm{H}_{2} \mathrm{O}$ than in $\mathrm{D}_{2} \mathrm{O}$. This last result confirms that an abstraction of a proton is involved in the mechanism.

Moreover, a power law is obtained when $\mathrm{k}_{\text {chem }}{ }^{3 \mathrm{MI}}$ are plotted against the water concentration: $\mathrm{k}_{\text {chem }}{ }_{3 \mathrm{MI}} \propto\left[(\mathrm{H}, \mathrm{D})_{2} \mathrm{O}\right]^{\mathrm{n}}, \mathrm{n}=5$ to 6 . This suggests that $3 \mathrm{MI}$ oxidation requires, besides the singlet oxygen, the simultaneous participation of a cage with an average number of $n=$ 5 to 6 water molecules.

This important reaction pathway could explain the puzzling result of $\mathrm{k}_{\text {chem }}$ and $k_{\mathrm{Q}}$ varying enormously with water concentration, which is not explainable by a direct ${ }^{1} \mathrm{O}_{2} *+3 \mathrm{MI}$ kinetic pathway described by the classic type II molecular mechanism.

The dependence on water concentration and the water isotopic effect, can be explained by the existence of a collisional intermediate of the form $\left[{ }^{1} \mathrm{O}_{2} * \cdots n(\mathrm{H}, \mathrm{D})_{2} \mathrm{O} \cdots 3 \mathrm{MI}\right]$ where at least an $\mathrm{O}-(\mathrm{H}, \mathrm{D})$ bond is weakened. However, the inclusion of these paths in Scheme 2 demands such a large number of kinetically parameters that the fitting procedure becomes practically impossible.

\section{ACKNOWLEDGEMENTS}

This work has been supported by a Portuguese financial program PRAXIS/C/SAU/35/96 and a PhD grant 12300/BD. We are grateful to Prof. S. B. Costa for the flash photolysis facilities.

\section{APPENDIX}

Bilski and co-workers ${ }^{10}$ had already verified that the ${ }^{1} \mathrm{O}_{2} *$ lifetime in water/dioxane solvent mixtures (in the absence of an oxidable substrate) is not fittable with the usual sum of the empirical solvent descriptors, such as $\pi, \alpha, \beta, \delta \mathrm{H}$, etc. In fact, there is no need for such solvent descriptors to explain the ${ }^{1} \mathrm{O}_{2}{ }^{*}$ lifetime behavior as a function of solvent composition. As already found by Rodgers, ${ }^{9}$ the deactivation of ${ }^{1} \mathrm{O}_{2} *$ in solvents or in binary solvent mixtures is due to a bimolecular collision mechanism. For solvent mixtures used in this work, the ${ }^{1} \mathrm{O}_{2}{ }^{*}$ deactivation rate is then given by Equation 12 . 
$\mathrm{k}_{\Delta}=\mathrm{k}_{\mathrm{o}}+\mathrm{k}_{\mathrm{Dx}}[\mathrm{Dx}]^{\mathrm{m}}+\mathrm{k}_{\mathrm{X}_{2} \mathrm{O}}\left[\mathrm{X}_{2} \mathrm{O}\right]^{\mathrm{n}}$

where $\mathrm{X}=\mathrm{H}$ or $\mathrm{D}$ and $\mathrm{m}, \mathrm{n}$ are the order of the deactivation relative to each one of the pure solvent and $[\mathrm{Y}]$ is the $\mathrm{Y}$ solvent molarity.

The parameters obtained fitting Equation 12 to Bilski data by least square method are: $\mathrm{m}=\mathrm{n}=1 ; \mathrm{k}_{\mathrm{o}}=0.0403 \mathrm{~s}^{-1} ; \mathrm{k}_{\mathrm{Dx}}=3213 \mathrm{M}^{-1}$ $\mathrm{s}^{-1} ; \mathrm{k}_{\mathrm{H}_{2} \mathrm{O}}=3980$ and $\mathrm{k}_{\mathrm{D}_{2} \mathrm{O}}=275 \mathrm{M}^{-1} \mathrm{~s}^{-1}$.

These results confirm Rodgers' observation for acetone/benzene and acetone- $\mathrm{H}_{6} /$ acetone- $\mathrm{D}_{6}$ mixtures concerning the bimolecular character of the singlet oxygen deactivation. ${ }^{7,9}$

The same kind of relation can also be found for other aqueous solvent mixtures. For instance, in water or deuterated water/acetonitrile mixtures, the experimental data from Bilski, fitted to Equation A.1, gives: $\mathrm{m}=\mathrm{n}=1 ; \mathrm{k}_{\mathrm{o}}=7.49 \mathrm{~s}^{-1} ; \mathrm{k}_{\mathrm{MeCN}}=748 \mathrm{M}^{-1} \mathrm{~s}^{-1} ; \mathrm{k}_{\mathrm{H}_{2} \mathrm{O}}=3739$ and $\mathrm{k}_{\mathrm{D}_{2} \mathrm{O}}=280 \mathrm{M}^{-1} \mathrm{~s}^{-1}$. The fitted curves are shown in Figures. 6 and 7. The only bad fit is explainable by an isotopic exchange between deuterated water and hydrogenated acetonitrile already reported in the literature. ${ }^{32}$

These results demonstrate that a collision mechanism with at least one hydrogen (or deuterium) abstraction is enough to explain the physical ${ }^{1} \mathrm{O}_{2}{ }^{*}$ deactivation in binary solutions, in the absence of an oxidable substrate. The rate constants for collision with water (deuterated or not) are independent of the organic pure solvent used in the mixture. The fact that $\mathrm{k}_{\mathrm{H} 2 \mathrm{O}}>>\mathrm{k}_{\mathrm{D} 2 \mathrm{O}}$ is compatible with a molecular mechanism involving an $\mathrm{X}$ ( $\mathrm{H}$ or $\mathrm{D})$ abstraction or, at least, an $\mathrm{O}-\mathrm{X}$ bond weakening. ${ }^{27}$ In literature, an electronic to vibrational energy transfer is claimed to have the same isotopic effect. ${ }^{7}$

\section{REFERENCES}

1. Davies, M. J.; Photochem. Photobiol. Sci. 2004, 3, 17.

2. Sá e Melo, T.; Averbeck, D.; Bensasson, R. V.; Land, E. J.; Salet, C.; Photochem. Photobiol. 1979, 30, 645

3. Foote, C. S. In Photosensitisation, Molecular, Cellular and Medical Aspects; Moreno, G.; Pottier, R. H.; Truscott, T. G., eds.; SpringerVerlag: Berlin, 1988, vol. H15, p. 125.

4. Sá e Melo, T.; Bazin, M.; Ronfard-Haret, J.-C.; Santus, R.; Photochem. Photobiol. 1993, 58, 19.

5. Wilkinson, F.; Helman, W. P.; Ross, A. B.; J. Phys. Chem. Ref. Data 1995, 24, 663

6. Zebger, I.; Snyder, J. W.; Andersen, L. K.; Poulsen, L.; Gao, Z.; Lambert, J. D. C.; Kristiansen, U.; Ogilby, P. R.; Photochem. Photobiol. 2004, 79, 319.
7. Schweitzer, C.; Schmidt, R.; Chem. Rev. 2003, 103, 1685.

8. Cosa, G.; Scaiano, J. C.; Photochem. Photobiol. 2004, 80, 159.

9. Rodgers, M. A.; J. Am. Chem. Soc. 1983, 105, 6201.

10. Bilski, P.; Holt, R. N.; Chignell, C. F.; J. Photochem. Photobiol., A 1997, 109, 243.

11. Michaeli, A.; Feitelson, J.; Photochem. Photobiol. 1994, 59, 284.

12. Lemp, E.; Pizarro, N.; Encinas, M. V.; Zanocco, A.; Phys. Chem. Chem. Phys. 2001, 3, 5222.

13. Palumbo, M. C.; Garcia, N. A.; Arguello, G. A.; J. Photochem. Photobiol., B 1990, 7, 33.

14. Lemp, E.; Zanocco, A. L.; Lissi, E. A.; Curr. Org. Chem. 2003, 7, 799.

15. Frimer, A. A.; Spectrum-J. State Gov. 2000, 13, 9.

16. Aubry, J. M.; Cazin, B. M.; Rougee, M.; Bensasson, R. V.; J. Am. Chem. Soc. 1995, 117, 9159

17. Carreno, M. C.; Gonzalez-Lopez, M.; Urbano, A.; Angew. Chem., Int. Ed. 2006, 45, 2737

18. Murov, S. L.; Carmichael, I.; Hug, G. L.; Handbook of Photochemistry, Marcel Dekker, Inc.: New York; $2^{\text {nd }}$ ed., 1993, p. 300.

19. Steinhoff, B. A.; Stahl, S. S.; J. Am. Chem. Soc. 2006, 128, 4348.

20. Bensasson, R. V.; Land, E. J.; Salet, C.; Photochem. Photobiol. 1978, $27,273$.

21. Bensasson, R. V.; Chalvet, O.; Land, E. J.; Ronfard-Haret, J. C.; Photochem. Photobiol. 1984, 39, 287.

22. Schwartz, B. J.; Rossky, P. J.; J. Chem. Phys. 1996, 105, 6997.

23. Sá e Melo, T.; Maçanita, A.; Prieto, M.; Bazin, M.; Ronfard-Haret, J.-C.; Santus, R.; Photochem. Photobiol. 1988, 48, 429.

24. Kamlet, M. J.; Abboud, J. L. M.; Abraham, M. H.; Taft, R. W.; J. Org. Chem. 1983, 48, 2877.

25. Casassas, E.; Fonrodona, G.; de Juan, A.; Anales de Quimica 1991, 87, 611

26. Wentworth, P. Jr.; Jones, L. H.; Wentworth, A. D.; Zhu, X; Larsen, N. A.; Wilson, I. A.; Xu, X.; Goddard III, W. A.; Janda, K. D.; Eschenmoser, A.; Lerner, R. A.; Science 2001, 293, 1806.

27. Pilling, M. J.; Seakins, P. W.; Reaction Kinetics, Oxford University Press: New York, 1995, p. 80.

28. Bardez, E.; Fedorov, A.; Berberan-Santos, M. N.; Martinho, J. M. G.; J. Phys. Chem. A 1999, 103, 4131.

29. Engdahl, A.; Nelander, B.; Science 2002, 295, 482.

30. Xu, X.; Muller, R. P.; Goddard III, W. A.; Proc. Nat. Acad. Sci. U. S. A. 2002, 99, 3376

31. Lemp, E.; Zanocco, A. L.; Günther, G.; J. Photochem. Photobiol., B 2001, 65, 165.

32. Heck, G.; Mileham, C.; Martin, G. J.; Analusis 1997, 25, 202. 